\title{
Public domain optics: experimental gems from pre-1923 textbooks
}

\section{Aaron Danner}

Aaron J. Danner, "Public domain optics: experimental gems from pre-1923 textbooks," Proc. SPIE 11143, Fifteenth Conference on Education and Training in Optics and Photonics: ETOP 2019, 1114318 (2 July 2019); doi: $10.1117 / 12.2523881$

SPIE Event: Fifteenth Conference on Education and Training in Optics and Photonics: ETOP 2019, 2019, Quebec City, Quebec, Canada 


\title{
Public domain optics: Experimental gems from pre-1923 textbooks
}

\author{
Aaron J. Danner*
}

\author{
Department of Electrical and Computer Engineering, 4 Engineering Drive 3, National University of \\ Singapore, 117583, Singapore
}

\begin{abstract}
The basic concepts of theoretical and experimental optics have remained largely unchanged since the 1890s. With the exception of the existence of the ethereal medium, interpretations and explanations of classical optical phenomena contained in introductory optics textbooks of the late 1800s and early 1900s are essentially modern, and textbooks from this era can provide a valuable source of teaching and learning material which can be adapted for modern coursework free of fear of copyright infringement. In surveying a number of such textbooks, a trove of interesting "chiefly by the lantern" experiments which would prove useful to any student of today have been found. This talk will describe a selected few such experiments which can be done without significant materials cost, perhaps involving minerals such as mica, tourmaline, and selenite.
\end{abstract}

Keywords: Talbot effect, mica, birefringence, textbooks

\section{INTRODUCTION}

There is an increasing number of free-for-download textbooks and textbook-like lecture notes in the field of optics and optoelectronics readily available. A survey of such materials conducted in early 2019 by the author found a large number of such learning materials readily available [1-47]. The copyright terms of such recent works vary considerably, sometimes allowing free use and rights of re-distribution, sometimes allowing free use but with restrictions on distribution and re-use, and sometimes unclear or complex rights. In any case, for the learner of optics, these materials can be invaluable. (The author took reasonable care to ensure that only legally available texts were counted.) In addition to the large number of recent efforts by authors and publishers to make more work available, pre-1923 textbooks are special because these works are now in the public domain in the U.S. (and in the vast majority of other localities as well). Many of these books have been scanned and are available for download or print-on-demand. Since the field of classical optics, including concepts such as geometrical optics, introductory physiological optics, interference, birefringence, and other topics which are usually taught to beginners is unchanged, these textbooks can provide a valuable source of teaching and learning materials without fear of breaching copyright; moreover, some experiments useful for learning basic optics which were painstaking in the late 1800 s are significantly easier now, and are perhaps not widely known. Some experimental texts from the late 1800's are especially interesting, because optics experiments were described without significant equipment needs. The books Light: A Course of Experimental Optics (Chiefly with the Lantern) by Lewis Wright (Macmillan, 1892) [20] and Practical Exercises in Physiological Optics by George J. Burch (Oxford, 1912) [23] are especially useful, along with an 1836 article by Talbot introducing what's now known as the Talbot Effect [47].

\section{THREE SAMPLE EXPERIMENTS}

\subsection{Polarization}

Imagine the following scenario in an introductory optics class: Teach first the concept of polarization, and then use two pieces of Polaroid to explain polarization in the standard way. But for students to truly understand polarization, ask the following question in an introductory optics class: How many ways can you think of to polarize light? And explain how each method works! For example, if no Polaroid film is available, explain how tourmaline can be used as a polarizer. Explain the Nicol Prism, Foucault's Prism, Iceland Spar (calcite), Ahren's Prism, the Glan Prism, the Rochon Prism, a "stacked-glass" polariscope or explain how a polished mahogany table can function as an analyzer. Wright [20] recommends 10-12 glass plates in the stack, with the bottom of the lowest plate blackened, as shown in Figure 1.

*adanner@nus.edu.sg

Fifteenth Conference on Education and Training in Optics and Photonics: ETOP 2019, edited by

Anne-Sophie Poulin-Girard, Joseph A. Shaw, Proc. of SPIE Vol. 11143, 1114318 - (c) 2019

SPIE, ICO, IEEE, OSA · CCC code: 0277-786X/19/\$18 · doi: 10.1117/12.2523881 

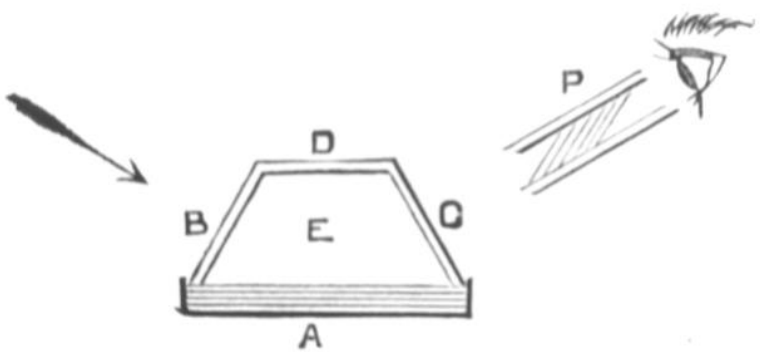

Figure 1. The stacked glass polariscope, reproduced from Ref. [20], Fig. 167. Understanding of this polarizer is slightly more difficult for students than other types of polarizers.

\subsection{Birefringence}

The use of mica or other minerals such as selenite, which are expensive, can offer interesting hands-on activities to students to demonstrate both thin film interference and birefringence. The idea was beautifully implemented in Ref. [20] but can be reproduced much more easily with two pieces of Polaroid (linear polarizing film). Figure 2 outlines the procedure of a simple experiment. Firstly, a book of muscovite mica can be very easily divided into very thin and transparent leaves. Since mica is birefringent, the method of using crossed polarizers can be used to illustrate a beautiful interference effect. With a single leaf of mica sandwiched between non-crossed polarizers, there is a small effect, but when the polarizers are crossed, an interference pattern resembling thin-film interference is set-up which depends on both the thickness of the film and the birefringence of the sample. This method may be useful in teaching both concepts, and may not be readily understood at first glance. The result from the author may not resemble the beauty of the 1892 work in which a vast assortment of beautiful patterns were designed using only mica sheets, but is fast and easy.

\subsection{Talbot Effect}

The Talbot Effect was first described in 1836 in Philosophical Magazine [47]; an excellent modern description of the effect (with a 2-dimensional grating) is available by Belin and Tyc [48]. The essence of the effect is that a collimated (or quasi-collimated) beam of monochromatic light shone through a grating with a lateral surface feature size of $a$ will produce self images at periodic distances of $2 a^{2} / \lambda$, the Talbot length. Intermediate distances produce beautiful patterns which make the effect interesting in an educational setting.

Although the effect may have been more difficult to observe in the 1800 s without a laser, it can be now easily created with a single laser pointer and a pair of binoculars, and any 2D stencil pattern with a reasonably small $a$ to give reasonable Talbot distances for visible light. (However, $a$ should not be too small so as to be similar to the wavelength.)

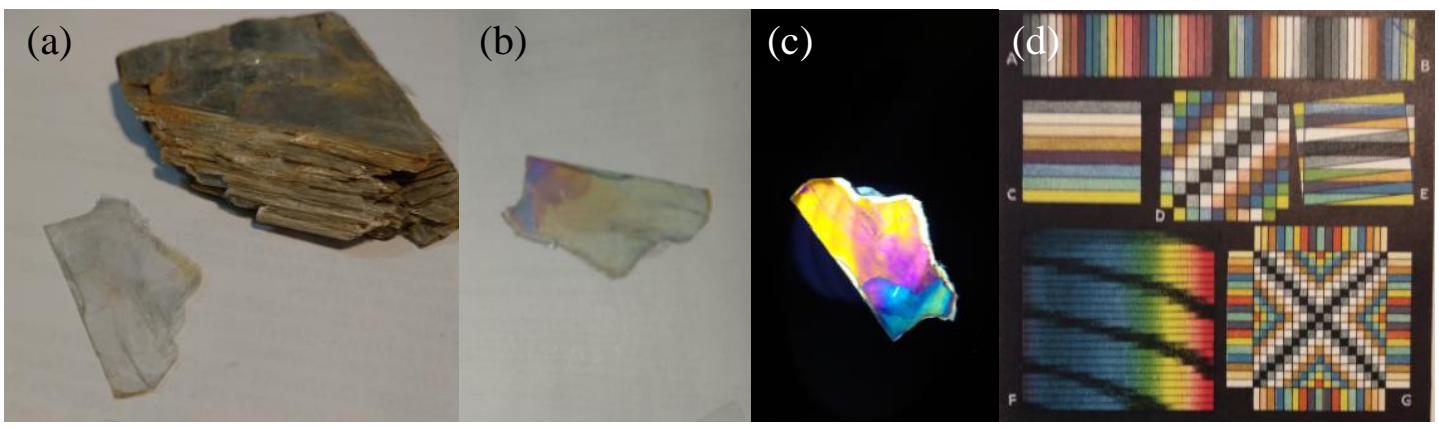

Figure 2. Experiment by the author: (a) A book of mica with one leaf cut away, (b) the leaf between parallel Polaroid pieces, (c) the leaf between crossed Polaroid pieces (illuminated from behind). (d) A similar setup with a more elaborate design in the 1892 reference [20]. 


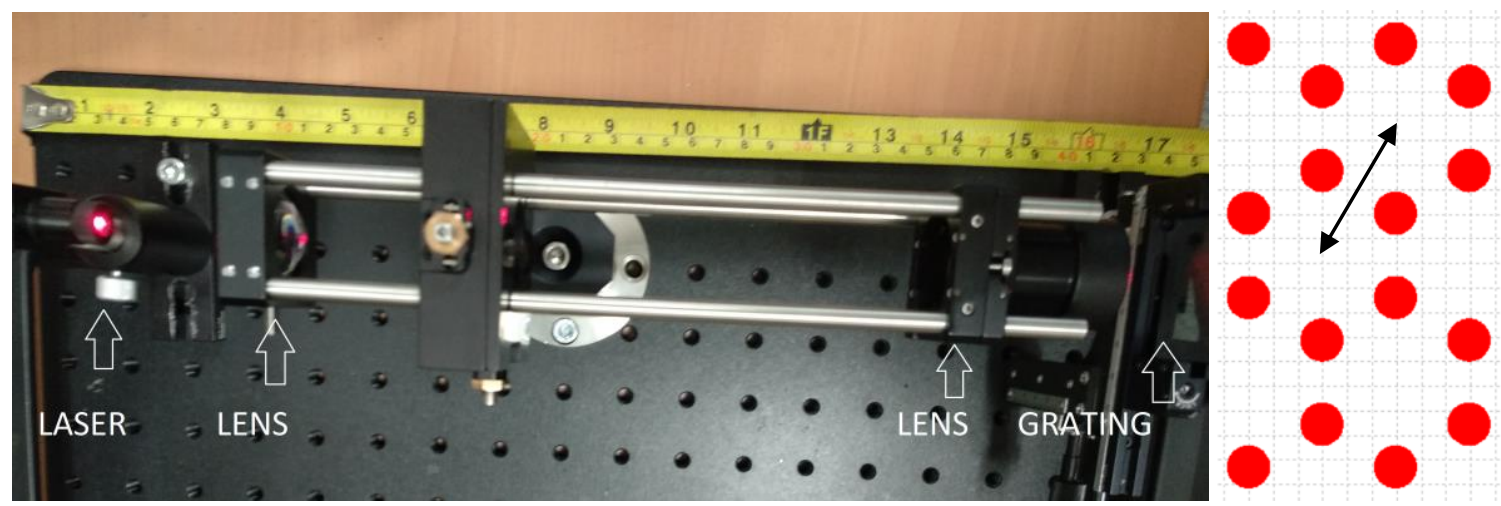

Figure 3. The beam is first expanded with a 2-lens telescope and then passes through the pattern. (One unit cell of the pattern used is shown to the right, where the red circles are open and the rest is opaque with chromium). The spacing between centers of the hexagonal array illustrated by the arrow is $0.72 \mathrm{~mm}$ and the radii of the red openings are $0.10 \mathrm{~mm}$.

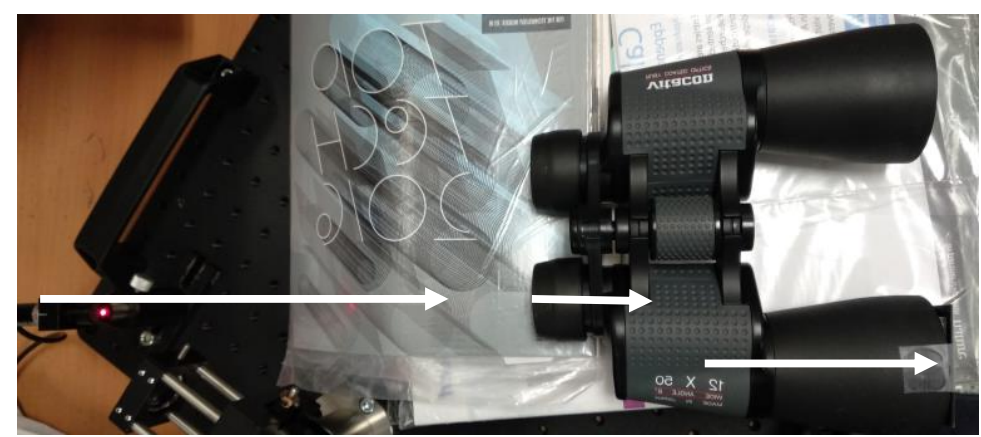

Figure 4. No optical table is necessary and no beam expander is necessary. In this case, a $12 \times 50$ binocular half acts as a beam expander.

A simple setup of an experiment to observe the effect is shown in Figure 3 built on an optical breadboard, consisting of a red collimated laser diode, followed by a beam expander (in this case, a Keplerian telescope configuration of two convex lenses), followed by a grating. The beam expander ensures a collimated beam, although it is possible for the setup to still function with a single lens which would cause the beam to diverge, although in that case the Talbot distance will be altered and the Talbot image will be magnified (and less bright). A Nikon D7100 DSLR camera with the lens removed was then used to capture images beyond the grating. The image sensor is $23.5 \mathrm{~mm}$ x $15.6 \mathrm{~mm}$ in size. These images are labeled with the approximate distances from the grating to the camera image sensor and are shown in the collection of Figure 5 (corresponding to the Figure 3 setup and a collimated beam). The images are low quality compared to those in reference [48] and the binoculars setup - the periphery of the patterns show diffraction (probably due to the size of the grating relative to the expanded beam), and there are beam artifacts caused by the [modal quality of the] laser itself. If the laser would be first filtered to improve the beam, it would look better, but this shows that a very simple setup is useful in educational settings. The images shown in Figure 6 correspond to the setup in Figure 3, but with the lens adjacent to the grating moved inwards to create a diverging beam and a magnified set of images. The images shown in Figure 7 correspond to the setup in Figure 4.

\section{ACKNOWLEDGMENTS}

T. Tyc is acknowledged for helpful discussions on the Talbot effect. The author acknowledges E. Cheung J. H. for fabricating the grating and funding from the Teaching Academy at the National University of Singapore. 


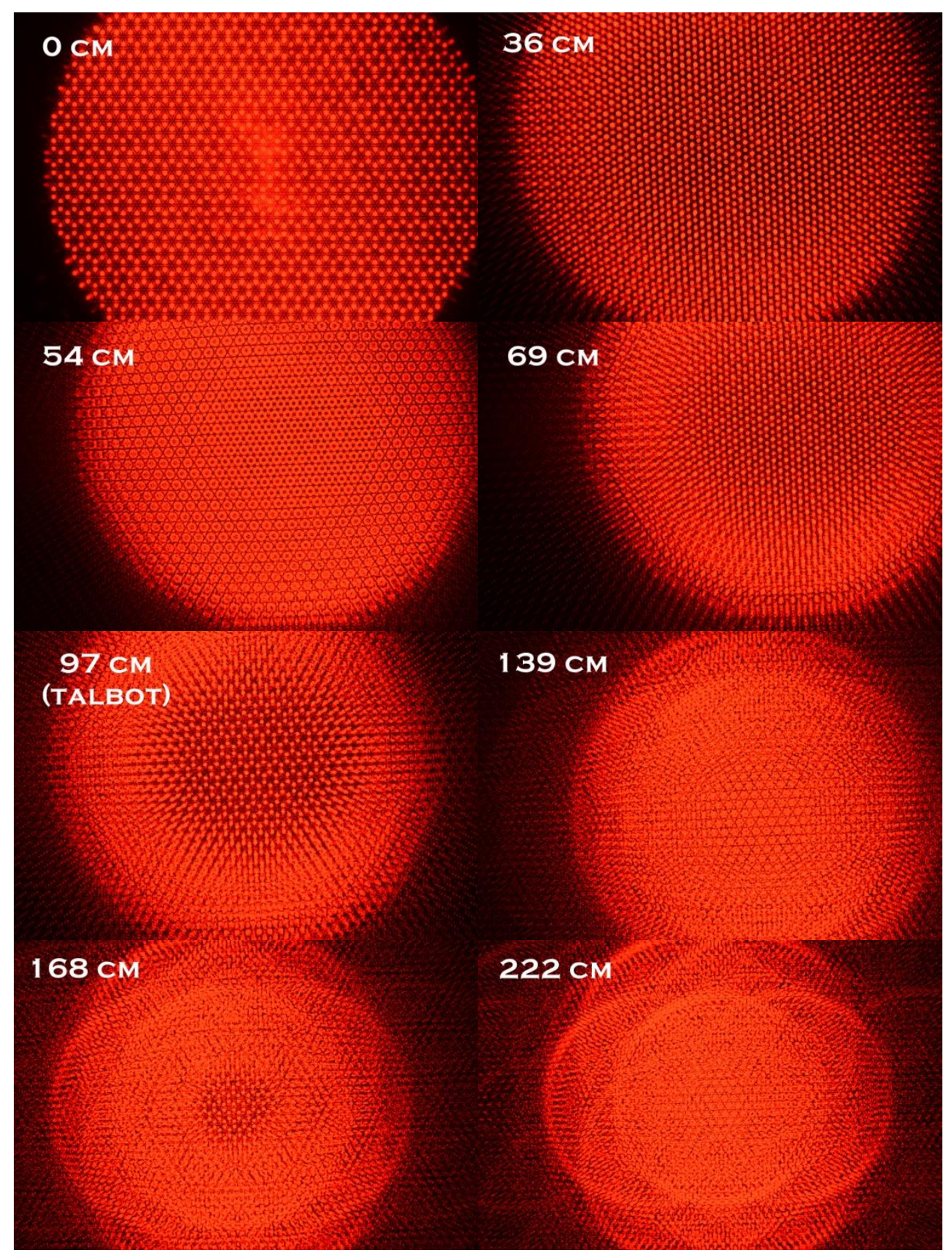

Figure 5. Direct observations at the image sensor with approximate distances from the grating marked with an expanded, collimated beam. Exact calculation of the Talbot distance for such a grating is described in detail in [48]. 


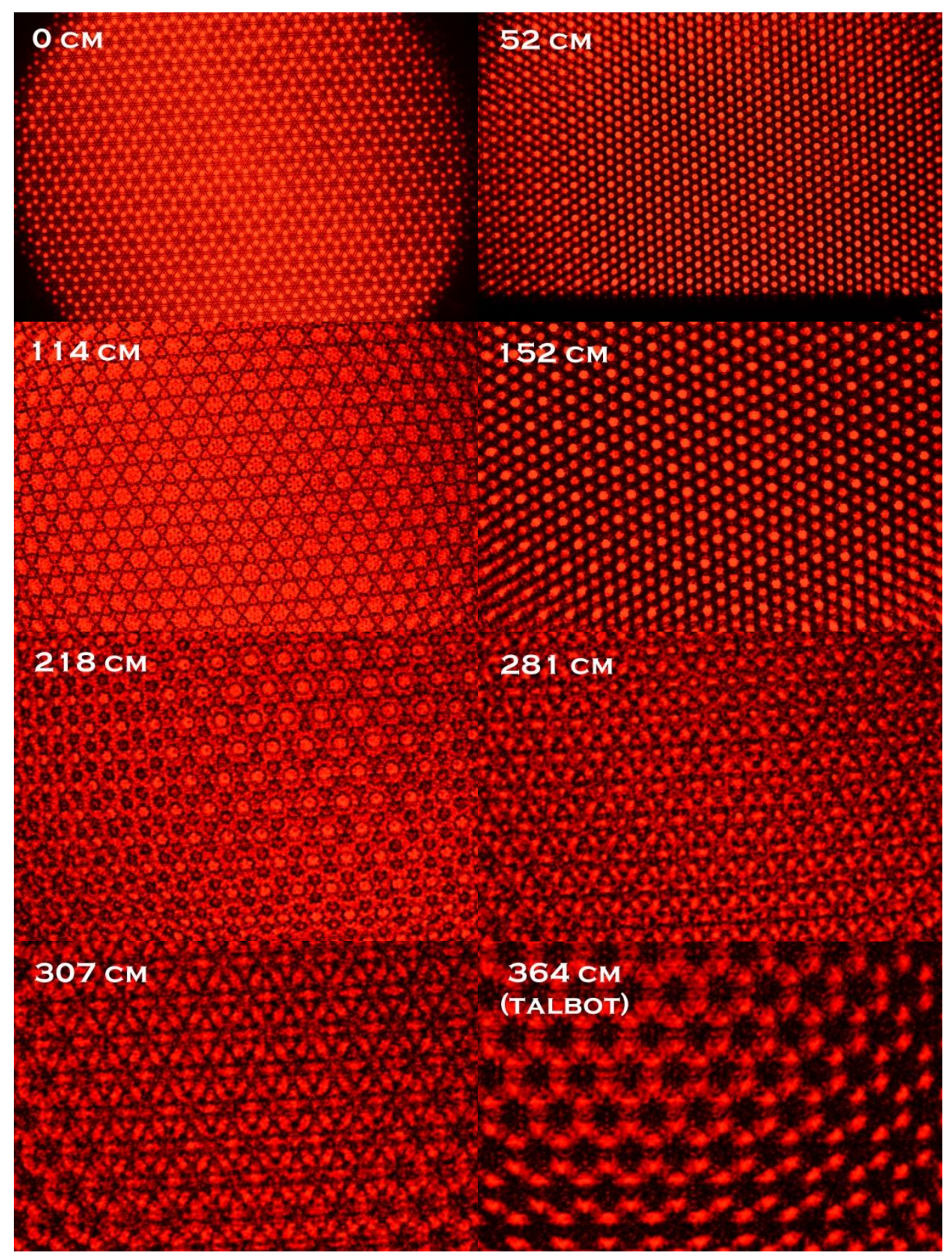

Figure 6. The diverging beam shows increasing magnification, and an increased distance to the Talbot image. 


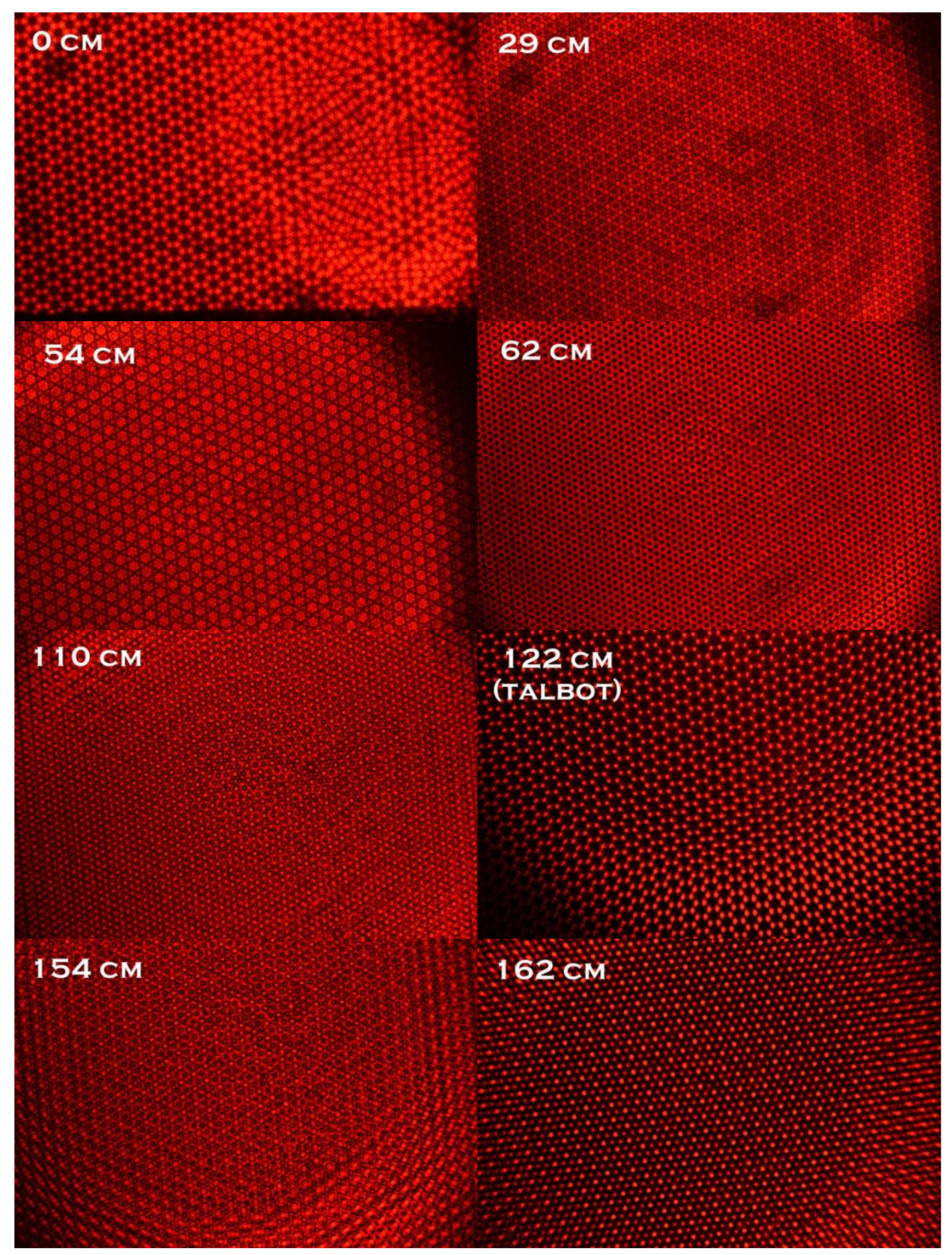

Figure 7. The aperture of the binoculars was more than twice the diameter of the expanded beam of the setup in Figure 5 resulting in improved images.

Proc. of SPIE Vol. $111431114318-6$

Downloaded From: https://www.spiedigitallibrary.org/conference-proceedings-of-spie on 26 Apr 2023 Terms of Use: https://www.spiedigitallibrary.org/terms-of-use 


\section{REFERENCES}

[1] Newton, I., [Optiks or a Treatise of the Reflections, Refractions, Inflections, and Colors of Light, 4th Ed], William Innys, London (1730).

[2] Stack, J., [A Short System of Optics, Principally Designed for the Use of Undergraduates in the University of Dublin, 3rd Ed], University of Dublin Press, Dublin (1820).

[3] Griffin, W., [A Treatise on Optics, 2nd Ed], Cambridge University Press, Cambridge (1842).

[4] Potter, R., [Physical Optics, Part II, The Corpuscular Theory of Light], Deighton, Bell, \& Co., London (1859).

[5] Potter, R. [Physical Optics or the Nature and Properties of Light], Walton \& Maberly, London (1856).

[6] Martin, B., [New Elements of Optics or the Theory of Aberrations, Dissipation, and Colours of Lights], London (1759).

[7] Wood, J., [The Elements of Optics: Designed for the Use of Students at the University, 4th Ed], Deighton \& Sons, Cambridge (1818).

[8] Farrar, J., [An Experimental Treatise on Optics], Cambridge University Press, Cambridge (1826).

[9] Coddington, H., [A Treatise on the Reflexion and Refraction of Light, being Part I of a System of Optics], Cambridge University Press, Cambridge (1829).

[10] Brewster, D., [A Treatise on Optics], Carey, Lea, \& Blanchard, London (1833).

[11] Harris, J., [A Treatise of Optics Containing Elements of the Science], B. White, London (1775).

[12] Rutherforth, T., [A System of Natural Philosophy being a Course of Lectures in Mechanics, Optics, Hydrostatics, and Astronomy], W. Thurlbourn, Cambridge (1748).

[13] Potter, R., [An Elementary Treatise on Optics, Vol. 1, 2nd Ed Revised], Taylor, Walton \& Maberly, London (1851).

[14] Jackson, I. W., [An Elementary Treatise on Optics], Barnes \& Co, New York (1848).

[15] Watt, A., [A New Theory of Optics as Regards Refraction of Dense Media and Vision], Kingston Chronicle, Kingston, Jamaica (1825).

[16] Martin, B., [A New and Compendious System of Optics], James Hodges (1740).

[17] Phelps, R., [An Elementary Treatise on Optics: Intended Chiefly to Elucidate], E. Johnson (1835).

[18] Powell, B., [A Short Elementary Treatise on Experimental and Mathematical Optics], D. A. Talboys, London (1833).

[19]Lorentz, H. A., [The Theory of Electrons and its Applications to the Phenomena of Light], B. G. Teuner, Leipzig (1916).

[20] Wright, L., [Light-A Course of Experimental Optics Chiefly with the Lantern], MacMillan \& Co., London (1892).

[21] Johnson, B. K., [Practical Optics for the Laboratory and Workshop], Benn Brothers, London (1922).

[22] Ramsey, A. S., [Elementary Geometrical Optics], G. Bell \& Sons, London (1920).

[23] Burch, G. J., [Practical Exercises in Physiological Optics], Clarendon Press, Oxford (1912).

[24] Laurence, L., [General and Practical Optics, 3rd Ed], School of Optics, London (1920).

[25] Percival, A. S., [Geometrical Optics], Longmans, Green, and Co. (1913).

[26] Mann, R. C. and Millikan, R. A., [Theory of Optics], Longmans, Green \& Co., London (1907).

[27] Parkinson, S., [A Treatise on Optics], MacMillan \& Co., London (1859).

[28] Lardner, D., [A Handbook of Natural Philosophy: Optics], Crosby, Lockwood \& Co, London (1878).

[29] Airy, O., [Geometrical Optics Adapted to the Use of the Higher Classes in Schools], MacMillan \& Co. (1870).

[30] Hopkins, W. B., [A Series of Figures Illustrative of Geometrical Optics], John Deighton, London (1851).

[31] Airy, G. B., [On the Undulatory Theory of Optics, designed for the use of students in the University], MacMillan, London (1866).

[32] Aldis, W. S., [An Elementary Treatise on Geometrical Optics], Deighton, Bell \& Co., London (1872).

[33] Van Monckhoven, D., [Photographic Optics: Lens and Enlarging Apparatus], R. Hardwicke (1867).

[34] Peatross, J. and Ware, M., [Physics of Light and Optics], https://optics.byu.edu/BYUOpticsBook_2015.pdf, (2015) (1 May 2019).

[35] Onuchukwu, C., [Fundamentals of Geometric and Physical Optics for Undergraduates], https://www.researchgate.net/publication/328538521_FUNDAMENTALS_OF_GEOMETRIC_AND_PHYSICAL_ OPTICS_FOR_UNDERGRADUATES/download (2015), (1 May 2019).

[36] Crowell, B., [Optics], https://www.fisica.net/optica/optics_textbook.pdf, (2000). 
[37] Steck, D. A., [Quantum and Atom Optics], http://atomoptics-nas.uoregon.edu/ dsteck/teaching/quantumoptics/quantum-optics-notes.pdf (2007).

[38] Jakobsen, K., [Thermodynamics of Light], https://arxiv.org/pdf/1805.03179.pdf (2018).

[39] Jones, R. V., [Optical Physics and Quantum Electronics], http://people.seas.harvard.edu/ jones/ap216/lectures/lectures.html (2000).

[40] Steck, D. A., [Classical and Modern Optics], http://atomoptics-nas.uoregon.edu/ dsteck/teaching/optics/opticsnotes.pdf (2006).

[41]Davidson, R. F. and Tinnell, R. W., [Unified Physics: Optics], Delmar, New York (1972).

[42] Keeling, J., [Light-Matter Interactions and Quantum Optics], https://www.standrews.ac.uk/ jmjk/keeling/teaching/quantum-optics.pdf (2013).

[43] Joannopoulos, J. D. et al., [Photonic Crystals: Molding the Flow of Light, 2nd Ed], Princeton University Press, Princeton (2008).

[44] Konnen, G. P., [Polarized Light in Nature], Cambridge University Press, Cambridge (1985).

[45] George, N. [Fourier Optics], http://www2.optics.rochester.edu/workgroups/george/FO_BOOK.pdf (2012).

[46] Ling, S. J., Sanny, J. and Moebs, W., [University Physics Vol. 3: Optics], OpenStax (2018).

[47] Talbot, H. F. "Facts relating to optical science," Philosophical Magazine and J. of Science 9 (26), 401-407 (1836).

[48] Belin, J., and T. Tyc, "Talbot effect for gratings with diagonal symmetry," J. of Optics 20, 025604 (2018). 